\title{
ARROYO ALMARAZ, A. (2008): LA LENGUA ESPAÑOLA \\ EN LOS MEDIOS DE COMUNICACIÓN Y EN LAS NUEVAS TECNOLOGÍAS. EDICIONES DEL LABERINTO, 493 PÁGS.
}

\author{
Alberto Rodríguez Lifante \\ Universidad de Alicante \\ alberto.rodriguez@ua.es
}

Desde hace tiempo, los profesionales del campo del Periodismo, la Comunicación Audiovisual y la Publicidad y Relaciones Públicas necesitaban una obra en la que se recogiesen contenidos de lengua española y que, así mismo, estuviesen enfocados de manera específica a estos estudios. En este sentido, el manual coordinado por el profesor de la Universidad Complutense de Madrid, Antonio Arroyo, surge como respuesta a esta demanda tanto de los alumnos como de los docentes que se dedican a estos ámbitos. Porque la presencia constante de la lengua en los medios de comunicación (radio, televisión, Internet) requiere una plasmación por escrito de sus características y errores más frecuentes, con el fin de clasificarlos y evitarlos. Todos estos elementos son objeto de análisis en el libro que reseñamos a continuación.

Así pues, este manual sirve de síntesis de los temas de lengua española para todos aquellos que la emplean en los medios de comunicación, las nuevas tecnologías o los ámbitos específicos. Y, de cara a la corrección de posibles errores, los autores se plantean similares objetivos a los del Diccionario Panhispánico de dudas, que citan textualmente, con cuyo apoyo teórico defienden los hábitos de corrección fijados en la norma, siguiendo los modelos de la escritura o del habla considerados cultos.

La obra está organizada en diez capítulos dedicados a la presencia de la lengua española en diversos ámbitos de los medios de comunicación, desde la prensa hasta la publicidad o las TICs. Cada uno de ellos corre a cargo de especialistas tanto en el campo de los medios de comunicación y de las telecomunicaciones, como de la filología. El cuerpo teórico que constituye cada capítulo también se complementa, por un lado, con actividades que pretenden ser una aplicación a cada uno de los temas que se abordan (pensada sobre todo para el público estudiante) y, por otro, con una breve bibliografía recomendada.

Los tres primeros capítulos están dedicados al español en la prensa y abordan los aspectos ortográficos, morfosintácticos y léxico-semánticos. El primero de ellos pretende ser un compendio sobre las cuestiones ortográficas que deben ser tenidas en cuenta por periodistas a la hora de redactar. La profesora María Elena Gómez Sánchez, de la Universidad Europea de Madrid, hace un repaso a las reglas de acentuación en la lengua española, los problemas que plantean los hiatos y los diptongos en estas situaciones y cuál es el sistema de acentuación de las diversas lenguas existentes en el ámbito español (el gallego, el euskera y el catalán). Las expresiones latinas o la doble acentuación son algunos de los puntos sobre los que hace 
especial hincapié, ya que suelen plantear dificultades entre los redactores. Le sigue un apartado dedicado a las mayúsculas, con el que intenta aclarar su uso en los diferentes contextos. Así también, se recogen las pautas para el uso de las abreviaciones (abreviaturas, acrónimos, siglas y símbolos), las cantidades, los numerales y, en último lugar, la puntuación y el estilo. A modo de colofón, como ya hemos anunciado, se plantea una serie de actividades y se recogen las referencias bibliográficas recomendadas, algo que obviaremos repetir en el análisis de los siguientes capítulos, pues se repite en todo ellos (a excepción del noveno).

En el segundo apartado, también referido al ámbito periodístico, la profesora $\mathrm{M}^{\mathrm{a}}$ Luisa Regueiro Rodríguez, de la Universidad Complutense de Madrid, aborda los aspectos morfosintácticos que caracterizan a la lengua española de la prensa; se parte del enunciado, oración o frase como unidad sintáctica hasta llegar a los sintagmas y a las palabras propiamente (estas últimas como unidades morfológicas). Por un lado, se presta especial atención a las proposiciones subordinadas, que suelen presentar dificultades de uso y, por otro, al sistema verbal, que constituye, sin lugar a dudas, uno de los puntos fuertes del capítulo, pues el verbo es una de las categorías gramaticales que con mayor frecuencia sufre cambios en el lenguaje periodístico. También presta atención a los diversos tipos de sintagmas (nominal, adjetival, preposicional y adverbial), empleando ejemplos procedentes del CREA para ilustrar sus usos. El uso de los corpus de textos sincrónicos estará muy presente a lo largo del manual, sobre todo porque se pretende dar cuenta de una muestra viva y real de la lengua, tanto en los medios escritos como orales.

El tercer capítulo, a cargo de Ana María Rodríguez Fernández, de la Universidad Complutense de Madrid, que cierra los dedicados a la prensa, trata de los aspectos léxico-semánticos. En él se examinan los neologismos y su formación, puesto que el lenguaje de la prensa es muy proclive a introducir en la lengua nuevas palabras y su influencia sobre la lengua común es enorme, debido a que estamos expuestos a su presencia constantemente. Ahora bien, puesto que en la propia lengua española disponemos de recursos para crear nuevas palabras, se recogen aquí los mecanismos de formación de palabras mediante la afijación (prefijación, sufijación y parasíntesis), la composición y el empleo de las siglas, sigloides y acrónimos. La autora no se olvida de los préstamos lingüísticos, así como de la metáfora, el eufemismo y el lenguaje políticamente correcto, que constituyen rasgos propios del lenguaje de la prensa.

El cuarto capítulo cambia de orientación y se refiere ya al tratamiento de los lenguajes específicos dentro del ámbito periodístico. En este sentido, la presencia de un lenguaje político, jurídico, literario o económico, entre otros, conforma también el periodístico. De ahí que se pueda hablar del uso de las lenguas de especialidad en este ámbito; lenguas específicas a las que debe enfrentarse el lector, espectador u oyente cada vez que entra en contacto con los medios de comunicación. Emilio Alejandro Núñez Cabezas, de la Universidad de Málaga, recoge las características propias de cada una de ellas, así como los errores más frecuentes en su uso, en la consideración de que el conocimiento de sus particularidades puede ser útil para el futuro redactor, locutor o presentador.

El capítulo quinto se centra en el ámbito publicitario y María Isabel Hernández Toribio, de la Universidad Complutense de Madrid, lo aborda desde la perspectiva de la lingüística aplicada, a pesar de que la publicidad ofrece la posibilidad de ser analizada también desde otras disciplinas. Partiendo de este enfoque, la autora explica cómo los diversos soportes, a través de los que se transmite el lenguaje publicitario (televisión, radio o prensa), condicionan la forma que éste adquiere. En esta línea, la autora hace referencia a los principales 
recursos lingüísticos para la persuasión propios del discurso publicitario. A modo de conclusión, se nos plantea cómo la publicidad está basada más en lo emocional que en lo racional, debido a que de este modo se consigue mejor el objetivo que plantea el código publicitario.

Los medios audiovisuales y su lenguaje son analizados en el capítulo sexto, de mano de Susana Guerrero Salazar (Universidad de Málaga), quien destaca cómo el lenguaje audiovisual está conformado por elementos de naturaleza muy diversa (sonidos, gestos, imágenes en movimiento, texto oral y texto escrito, entre otros muchos), todos ellos comentados en los soportes a través de los que tienen difusión: la televisión, el cine, el vídeo y la red. La autora plantea otros apartados dedicados a la importancia que tienen aspectos como los planos de las imágenes, los ángulos, el ritmo, la luz, los colores o los gestos, por un lado, y las funciones del sonido y del texto escrito, por otro. También se habla de dos ámbitos en los que tiene especial relevancia el lenguaje audiovisual: el televisivo y el cinematográfico, sobre los que pretende dar una nómina de errores comunes, que afectan a los diversos niveles de la lengua; no deja de lado, no obstante, aspectos como el guión, la traducción, el doblaje y el subtitulado, referidos todos ellos al ámbito cinematográfico.

Jesús Pérez García, de la Universidad de Valladolid, dedica el capítulo séptimo a las nuevas tecnologías (TICs). El lenguaje que se emplea en el soporte tecnológico está marcado por una serie de factores, como la inmediatez y la interacción rápida y fluida. En este sentido, los medios electrónicos, es decir, los chats y los mensajes de texto, entre otros, han introducido una serie de modificaciones en la lengua y en el modo de expresarse. Por un lado, han supuesto la combinación de la lengua oral y escrita y, por otro, han favorecido la penetración de innovaciones léxicas y nuevas normas ortográficas. Por supuesto, en los últimos años han proliferado no sólo los chats, sino también las conocidas redes sociales, los blogs y los podcasts (a cada uno de los cuales el autor dedica un apartado). Los elementos pragmáticos cobran relevancia en una sociedad en la que el formato digital nos invade y de ello da cuenta este capítulo. De ahí que en los medios de comunicación, tal como afirma el autor, y especialmente en la publicidad, se tomen prestadas las formas propias de las nuevas tecnologías con fines persuasivos. Al fin y al cabo, el público, sobre todo joven, está familiarizado con este «código» tecnológico y, por ello, el uso de la lengua es resultado de su adaptación a dichas circunstancias.

El medio radiofónico también encuentra su espacio en este manual, como no podía ser de otro modo, en el capítulo octavo. Su autora, Antonia María Medina Guerra, de la Universidad de Málaga, dedica estas páginas a las particularidades de la lengua empleada en la radio. De hecho, el uso de la lengua cobra mayor importancia en este medio, ya que a través de la voz se consigue persuadir, transmitir y, en definitiva, comunicar. Por ello, se hace necesario el análisis ortológico del sonido (aspecto tratado con bastante profundidad, a través de un estudio del sistema fonético y fonológico del español), las variedades dialectales y lo que el autor denomina «desviaciones ortológicas». El autor se ocupa del modo en que son pronunciadas las palabras, haciendo especial hincapié en el acento y la entonación de la frase. Todos estos elementos suprasegmentales cobran especial relevancia cuando nos referimos a la radio, en la que también debe cuidarse la redacción. De una mayor o menor preocupación por la redacción dependerá también que el oyente asimile la información que se está transmitiendo. Se requiere, por tanto, una lectura por parte del locutor que facilite la comprensión de los datos. De ahí que el conocimiento teórico de estos elementos ayude a mejorar el uso de la lengua. 
El capítulo noveno, a cargo de Antonio Dueñas Martínez de la Universidad Complutense de Madrid, se centra en la Retórica clásica y Pragmática, porque según su autor, constituyen un eslabón imprescindible dentro del ámbito de los medios de comunicación. Del buen uso de la palabra y la elaboración del discurso dependerá la consecución de sus objetivos. Por ello, este capítulo analiza los orígenes, las fases y las figuras retóricas más relevantes para tener un mejor conocimiento del uso de la lengua. Tras el análisis de la Retórica, el autor centra su atención en la Pragmática, como disciplina que pretende explicar el uso de la lengua vinculada a sus diversos contextos de uso. También se hace un repaso a los orígenes de esta disciplina, así como a sus escuelas (la norteamericana y el Círculo de Viena) y las diversas teorías que han surgido en torno a la Pragmática.

El último capítulo tiene como eje la dimensión sociolingüística en particular por lo que se refiere al contacto de lenguas en los medios de comunicación. El caso del español en este sentido es paradigmático, debido a la presencia de otras lenguas en nuestro Estado, tales como el euskera, el catalán y el gallego. El análisis de esta situación de mano de Antonio Arroyo Almaráz, coordinador de este manual y profesor de la Universidad Complutense de Madrid, se basa en la prensa escrita, observando qué presencia tienen dichas lenguas y de qué modo confluyen con el español. A este respecto, es interesante resaltar qué papel presentan estas lenguas en la prensa escrita. Con el fin de ilustrar la situación sociolingüística, se hace referencia a las voces y los topónimos más comunes que aparecen en la prensa escrita de las diversas regiones donde se habla el catalán, el gallego y el euskera. Encontramos al final de este capítulo dos anexos con referencia los términos toponímicos más comunes que suelen aparecer en la prensa en las diversas lenguas que hay en España, así como los antroponímicos.

En definitiva, debido al papel de los medios de comunicación en nuestra sociedad, se hacía necesaria una publicación de estas características. De ahí que el trabajo en equipo de especialistas dentro del campo de la comunicación, así como de filólogos convierta a este manual en una obra magnífica, tanto por su profundidad, por un lado, como por su claridad. La presentación de los contenidos en función de los ámbitos de uso de la lengua en los medios de comunicación permite una revisión rápida de los temas más relevantes destinados a los futuros profesionales de los campos de la Comunicación y las Ciencias de la Información. Se trata, por tanto, de un compendio muy útil para todos aquellos, tanto docentes como estudiantes, que quieran conocer los entresijos de la lengua española en los medios de comunicación. 